\title{
Optimizing oil and gas field management through a fractal reservoir study model
}

\author{
Mukhtar Habib $^{1} \cdot$ Yao Guangqing ${ }^{1}$. Congjiao Xie $^{1} \cdot$ Samba Prisca Charles $^{4}$. \\ Hamza Jakada ${ }^{2}$ Musa Salihu Danlami ${ }^{1}$ Hifzullah A. Ahmed ${ }^{3,5}$. \\ Ibrahim Abdullateef Omeiza ${ }^{2}$
}

Received: 3 June 2015/ Accepted: 4 May 2016/Published online: 10 May 2016

(c) The Author(s) 2016. This article is published with open access at Springerlink.com

\begin{abstract}
Integration among geophysics, geology, reservoir engineering, geochemists, geomechanics and management is truly essential, but needs some specific approaches and methodologies for developing and calibrating a study model capable of dealing with all and each of these aspects. The ability for a multitask project team to easily search, modify, visualize and/or analyze a multidisciplinary study results in a quick, responsive and easily comprehendible manner is still a problem of the petroleum industry. In this work, various modeling workflows were examined so as to highlight unavoidable interdependencies between these multidisciplinary specialists in the process of oil and/or gas reservoir studies. The traditional multidisciplinary working methods which were hitherto available are examined and some lapses identified. An optimized integrated study approach was further proposed. The optimized integrated approach is expected to have tremendous advantages in terms of improving the quality as well as flexibility of oil and gas reservoir studies, a working time reduction, and is expected to serve as a single
\end{abstract}

Mukhtar Habib

mukhtarhabib102@gmail.com

1 Key Laboratory of Tectonics and Petroleum Resources, Ministry of Education, Faculty of Earth Resources, China University of Geosciences, Wuhan 43007, Hubei, China

2 School Environmental Studies, China University of Geosciences, Wuhan 43007, Hubei, China

3 Department of Geology, China University of Geosciences, Wuhan 43007, Hubei, China

4 Petroleum Exploration and Production Research Institute of Sinopec, Beijing, China

5 MAUTECH, Yola, Adamawa, Nigeria final approach that can be adapted or used to tackle reservoir study problems.

Keywords Integration $\cdot$ Reservoir $\cdot$ Model $\cdot$ Management · Geophysics · Geology

\section{Introduction}

The world's average oil recovery factor is estimated to be $35 \%$ (Babadagli 2007). More oil recovery will without doubt depend on the availability and utilization of best technological practice as well as efficient reservoir management and economic strategies. Indeed, this obligates the need for improving the effectiveness of reservoir modeling and performance. According to Doublet et al. (1995), poor oil and/or gas reservoir studies can result in operational problems as well as economic imbalance, such as

- Low reservoir energy.

- Problems associated with discontinuous pay intervals.

- Vertical and lateral inconsistencies in reservoir properties.

- Low recovery factor.

Some operational problems associated with this kind of reservoirs include

- Poor or inadequate completion or stimulation.

- Early water break through.

- Poor reservoir sweep efficiency.

- Channeling of injected fluids due to preferential fracturing caused by excessive injection rates.

- Poor data quality.

If the most productive areas of a reservoir can be accurately identified by combining the result of a 
multidisciplinary study, then an optimized integrated study model can be applied to enhance reservoir performance, thereby increasing the overall average recovery factor.

Reservoir study is a system that covers various fields of specialty like engineering, geology, geophysics, petrophysics, geochemistry, drilling, logging and management. This involves the application of various kinds of static and dynamic data. An efficient reservoir study deals with integrating these specialties and/or data for a detailed comprehensive analysis so as to ultimately define best practice in exploration, appraisal, development, production and abandonment. On the one hand, each of this disciplines represent unique type of problem that require the attention of a specific professional, while on the other hand, reservoir studies extend on the entire stages that is from exploration down to abandonment. As a result, reservoir studies are always in need of multidisciplinary collaboration and/or integration. However, many challenges are continuously putting it into question; these include complexity of geological settings, enormous amount of data, organizational structures, tools, operations management and many other factors. As a result, inconsistencies are common, thereby making the process iterative. With this development, reservoir studies need multidisciplinary collaborative working in a highly flexible interaction platform. Many authors such as Zhang (2005) and Zhao et al. (2010) have made tremendous attempts to improve the situations caused by these challenges.

In this paper, we contributed our quota by first of all starting with an extensive review of the important stages involved in oil and/or gas reservoir studies, as well as highlighting some challenges evolving in the project life span. Some study models applied in recent times where observed together with their lapses, and finally, an optimized conceptual study was designed and proposed.

\section{Literature review}

\section{Static and dynamic reservoir modeling}

The aim of this section is to make the reader understand the volume of work required in developing a reservoir model, the enormous amount of data, the variety of specialty and specialist required, the care that needs to be applied and the close integration required among personnel of different professional background. We started from data acquisition through reservoir static and dynamic studies to development planning. Data acquisition forms the very beginning of a reservoir study (Sawaryn et al. 2011), in which variety of information is collected for evaluation. Data such as satellite images of the region, regional stress/strain data, seismic data, available core and well-logging data, production history, rock fluid interaction, equilibrium data, fluid PVT and many more. This continue to accumulate as the project continue to get matured.

After initial data acquisition, the next step is top (external boundaries) picking and mapping, and this involves the geophysical interpretation of seismic data set $(2 \mathrm{D}$ or 3D) usually coupled with an understanding of reservoirs sedimentology, thus allowing the further interpretation of geological trend of the reservoir understudy. The seismic features obtained are then changed into depth domain from the initial time domain, and this is done by a defined velocity law, in which the application of all data for seismic well calibration (synthetic seismogram) is the fundamental strategy for obtaining optimum result in the depth conversion (Chen and Oliver 2014; Gunning and Paterson 2001).

Based on the synthetic seismogram profile (Møyner and Lie 2014) obtained, the definition of tops and bottoms of the reservoir layers is achieved and the model development begins. Horizons and faults are continuously identified and mapped to be used at a later period during the grid construction.

According to Cosentino (2001), fault modeling is the most important aspect of the structural modeling because of its impact on reservoir compartmentalization which can have a direct effect on reservoir fluid flow, thus affecting the dynamic simulation model to be applied for future development of the reservoir. But only a combination of all available data gives a clear picture of the fault network, and in that case, the seismic data combined with well logs and production data should be calibrated.

The next step in the static reservoir modeling process is the stratigraphic modeling which is one of the most important aspects, because its result is very vital to the overall accuracy of field development. Modern application on this area follows the principle of sequence stratigraphy (Catuneanu 2002), which predicts the geometry of the reservoir based on sea level changes which depends on sedimentation pattern. On these bases, sequences of different hierarchical order are identified within a geological time zone separated by sequence boundaries which represent unconformities or maximum flooding surfaces. These surfaces are the most important reference points (markers) that the reservoir geologist needs. Where it is not convenient to apply the sequence stratigraphy principle, then basic well to well-correlation method in terms of real depth or with respect to a reference level can be applied (Habidin and Yusof 2012).

A good stratigraphic model allows us to understand the chronostratigraphic framework which is directly related to fluid flow in porous media, thus having a severe effect on the simulation model to be applied for the field development strategy. 
Facies modeling consists in populating the developed model with the appropriate facies distribution. These facies are identified on the bases of data gathered from the wells using specific classification criteria and subsequently distributed on the developed structural and stratigraphic model using some algorithms (Mardani et al. 2013; Panfili et al. 2012). The reason behind facies modeling is that petrophysical properties of a reservoir are closely related to the lithologic facies, thus becoming a basis for petrophysical modeling (Knackstedt et al. 2013; Le RavalecDupin et al. 2011).

Petrophysical modeling basically deals with quantitative study of the porous space in reservoir rock, an aspect of great importance in oilfield development because it forms the basis for reservoir fluid flow. The property of porous media is closely related to its mineralogy, texture and granulometry. These in turn are the functions of the depositional environment and the postdepositional activities like cementation, digenesis, fracturing and dissolution which might have effect on the rock after formation (Fitch et al. 2013; Zett et al. 2010). In this case, a close integration between geologist and petrophysicist is required.

Petrophysical properties such as porosity and fluid saturation are the most important parameters controlling the amount of hydrocarbon in the reservoir, while permeability controls the reservoir fluid flow capacity (Worthington and Cosentino 2005). Initial values for petrophysical application are derived from core samples and well logs, while there distribution on the model is controlled by statistical or deterministic methods (Merletti and Torres-Verdin 2010; Worthington 2011). With this model available, static reserve estimation can be carried out using variety of methods. We propose a workflow for static reservoir modeling in Fig. 1. The next stage is grid coarsening and up-scaling, and the geological model is usually developed on fine-scale grids which are not suitable for dynamic modeling. As a result, coarser model is developed to be used for dynamic simulation. In line with the above, various techniques have been proposed for calculating average grid value to be used for simulation grid (Aavatsmark et al. 2010; Mallison et al. 2014; Wu and Parashkevov 2010). Having obtained the grid ready for numerical simulation, the formulation of the reservoir dynamics begins. In dynamic reservoir modeling, different methods can be applied in determining dynamic reservoir behavior. Currently, among all the existing methods, the numerical simulation approach is the most powerful and more accurate in terms of parameter estimation and production forecast based on different development scenarios (Benetatos 2010; Delshad et al. 2011; Xie et al. 2009). As discussed earlier, the static model forms the backbone for numerical simulation; thus, the developed geological model coupled with production history, fluid PVT data, equilibrium data and rock fluid interaction properties can be used for evaluating dynamic reservoir behavior. We propose a workflow for dynamic reservoir modeling in Fig. 2.

The initialization process requires inputting the initial saturation and pressure distribution data. This is required for cross-checking the reserve estimation performed during the static model. History matching on the other hand deals with model calibration based on pressure and production data. Once the calibration is done, the development plan of the field can be achieved based on different production scenarios. Thus, economic strategies can be mapped.

For a more accurate result, regional data form an important aspect that should be accounted for; therefore, a better model can be achieved when integrated with satellite imageries and/or geomechanical data ( $\mathrm{Gu}$ et al. 2011; Vidal-Gilbert 2010).

\section{Reservoir geomechanical modeling}

Historically, geoscientist applies constant values or pressure-dependent variables in order to justify for rock mechanics during the process of most reservoir simulation practice. In essence, reservoir fluid flow cannot be separated from rock mechanics (Thomas et al. 2003). As a result, a rigorous reservoir dynamic model should include concurrent solution of multiphase flow and rock mechanics. It should also balance the interdependence between these two aspects. Geomechanical models provide data related to the effect of stress/strain generated in the reservoir as well as its surroundings (Warpinski et al. 2013).

The physical effects of stress variations, like porosity/ permeability changes and faults re-activation, cannot be neglected due to its direct link with the performance of the reservoir formation as well as safety, especially with respect to formations that are very sensitive to stress (Kim et al. 2013). Therefore, geomechanical applications require a coupling of fluid flow models together with stress data.

The geomechanical model has a strong affiliation to the static and dynamic models described in the previous section, because it encompasses the rock and the fracture features of a reservoir. A static model for dynamic analysis only requires a smaller scale when compared with a static model designed for geomechanical consumption. This is certain because the primary aim of oil and/or gas reservoir study is to enhance production. Therefore, the domain of investigation is centered on the hydrocarbon-bearing formation. In the case of geomechanical analyses, a static model at the regional scale is required so as to consider the stress and strain impacts of the surrounding formations on reservoir rock. Therefore, geomechanical model is required to exceed the reservoir dimensions to include the surrounding formation. See Fig. 3 for image. 


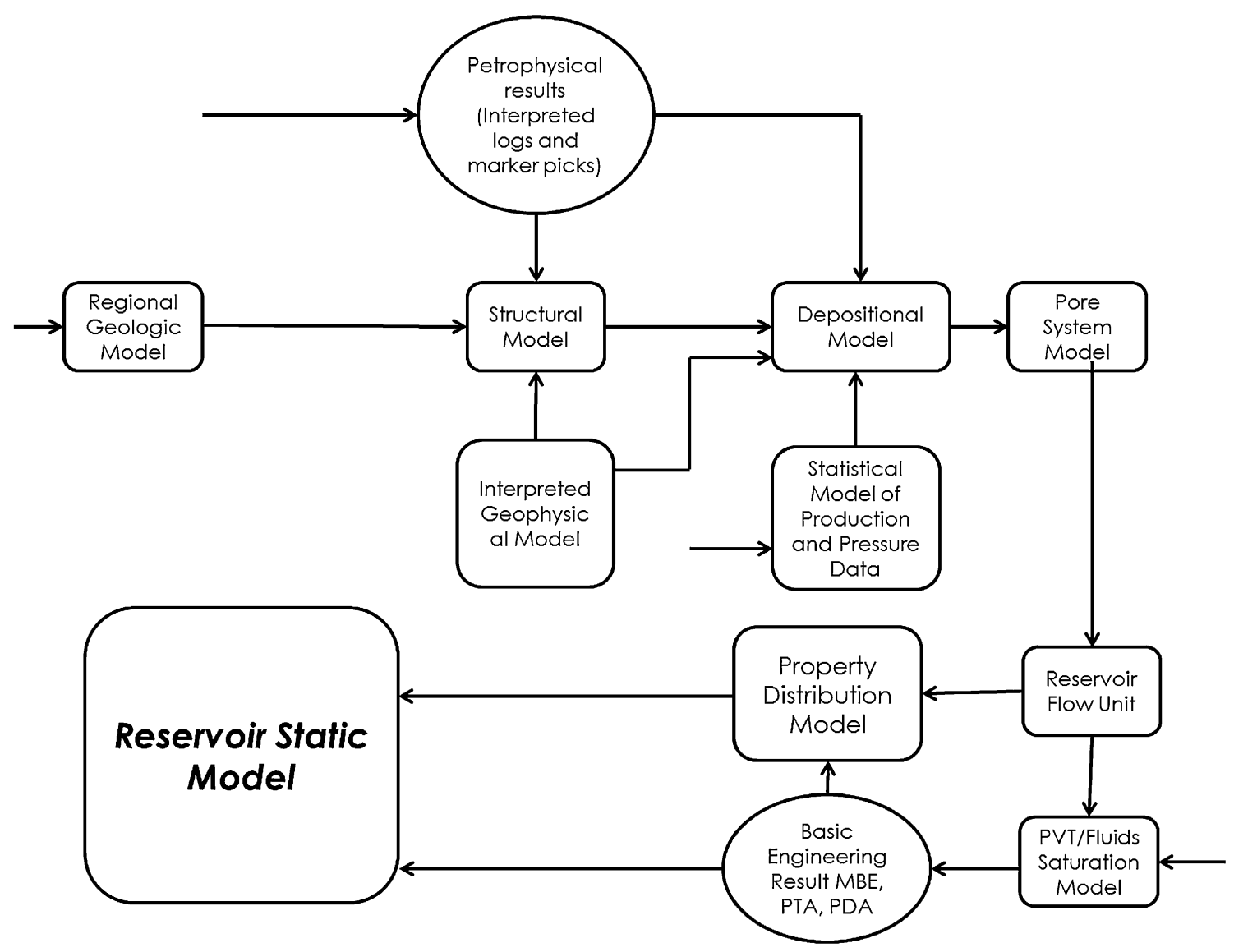

Fig. 1 Static reservoir modeling

A workflow was established by Baker Hughes Reservoir Development Services (RDS) as described in Wouter van der Zee et al. (2011) with respect to the geomechanical modeling workflow as shown in Fig. 4. The workflow allows for a detailed evaluation of the stress field which is uncommon to the oil and gas industry.

\section{Reservoir study models}

\section{Standalone reservoir studies}

Historically, reservoir studies are carried out in a linear approach. The procedure applied for many years by specialists and managers is presented in Fig. 5. Here, every aspect of a reservoir modeling has to be carried out separately. Results obtained are handed from one specialist to the other without much interconnection or adequate information flow.

Each and every specialist involved in the study has to provide data and/or result that are very reliable so as to reduce uncertainty as much as possible. This approach is so much dependent on the accuracy of each and every individual specialist, which might not be guaranteed.
Meanwhile, this approach showed several limitations, particularly when there are inconsistencies during data processing and/or interpretation. As a result, there is a need to make a consistent re-evaluation of all study model parameters.

\section{Integrated reservoir studies}

Within the last two decades, the values for an integrated reservoir studies have been recognized given the lapses in the standalone reservoir modeling approach. Different specialists have realized that they depend on each other and their goal can be achieved with each other's support. Working as a team, they feel a sense of ownership for their jobs because they are committed to the goals they help to establish. They work more effectively and efficiently as a team than as individuals, and thus, there synergy realizes a whole greater than the sum of its parts.

Integrated reservoir studies have been conducted for various purposes. An example is that of Huang et al. (2011), which conducted a successful integrated reservoir studies on the LaBerg Project. They developed a geologi$\mathrm{cal} /$ petrophysical model, evaluated the past and reservoir 


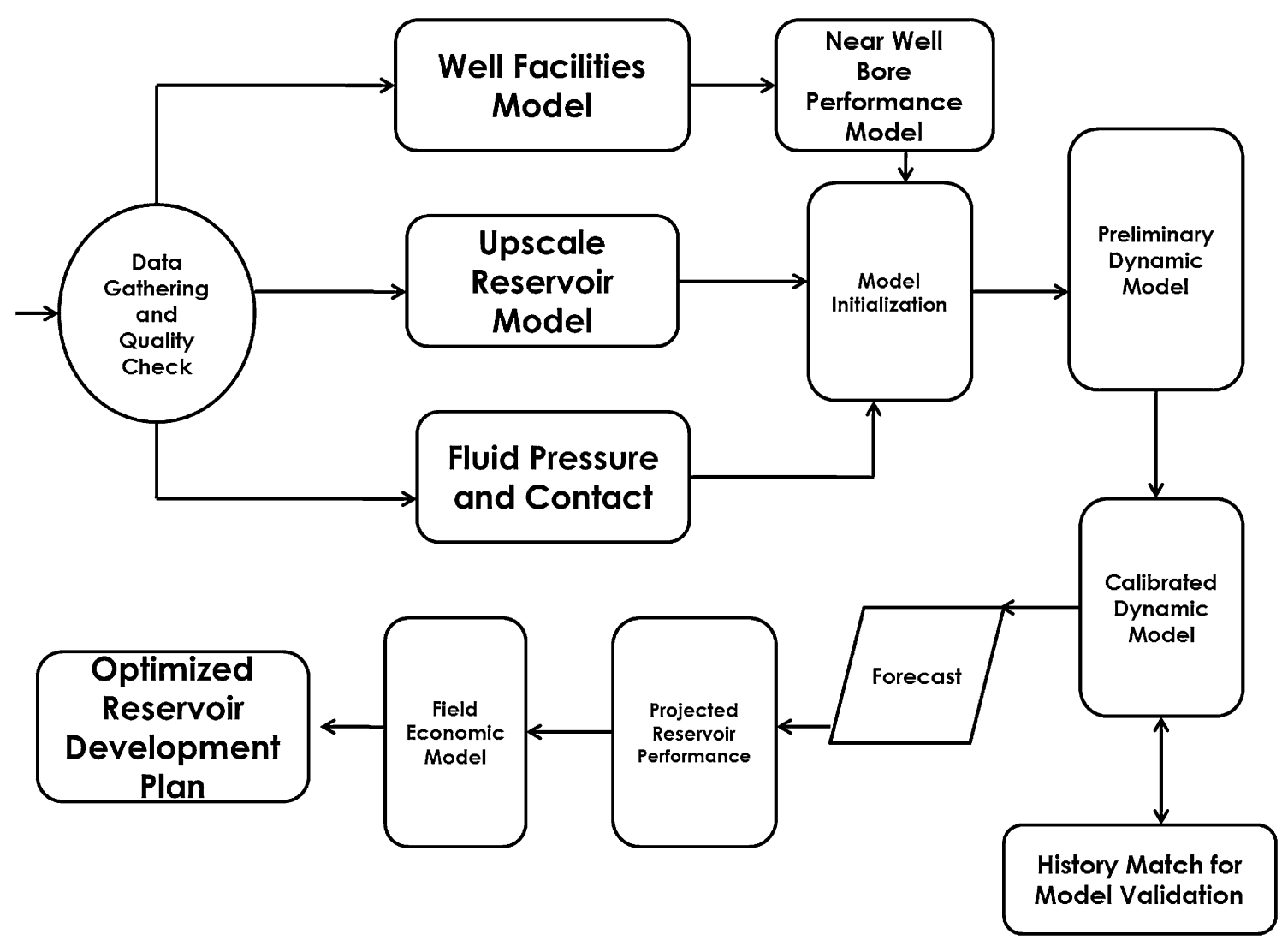

Fig. 2 Dynamic reservoir modeling workflow

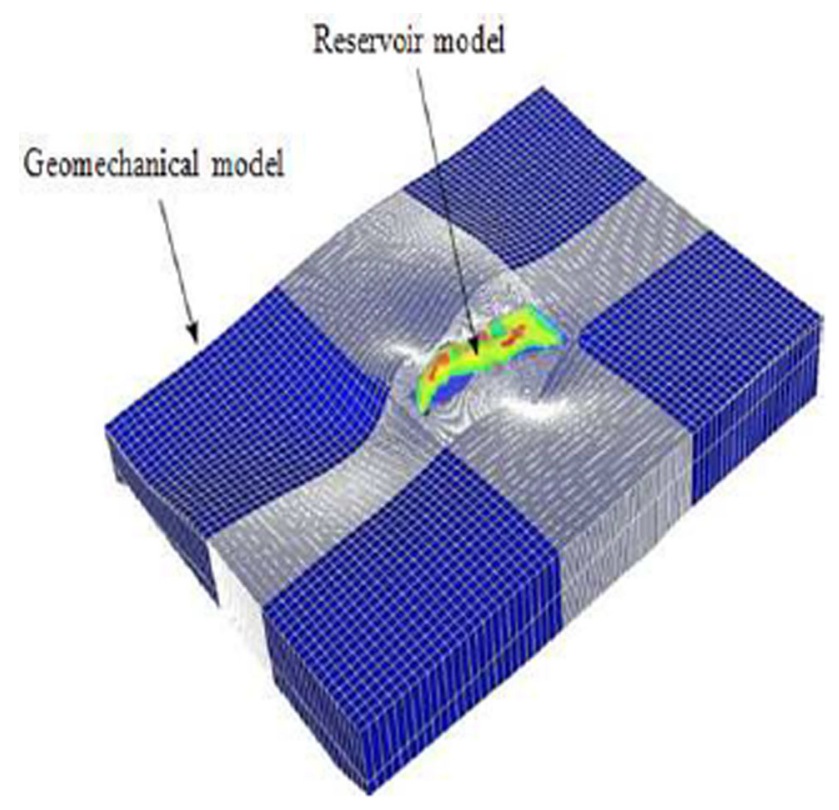

Fig. 3 Difference between geomechanical model and a reservoir scale model (adopted from Benetatos 2010) performance in the case of various operating plans and finally made recommendations on the bases of technical and economic interest.

Again, in the beginning of the year 2000, LUKoil and PetroAlliance finished a magnificently applied integrated reservoir studies in the western Serbarian basin, which included some large oil fields in Russia and the former Soviet Union. They developed a detailed 3D geological model of Vatyogan's six reservoirs which ranges from the age of Upper Jurassic to Upper Cretaceous and covers a relatively large depositional environment. With this model, they estimated reserves and prepared a field development program (Farag et al. 2010).

In its traditional context, members of multidisciplinary team formed for integrated reservoir studies meet periodically to discuss the problems and progress, fix possible disagreements as early as possible and solve the problem in a timely and effective manner, thus avoiding the inconsistent result reached by different specialists. The workflow for this kind of approach is shown in Fig. 6. This periodic integration lacks efficiency, especially in terms of data flow and communication at every step of the project life. 
Fig. 4 3D geomechanical modeling workflow

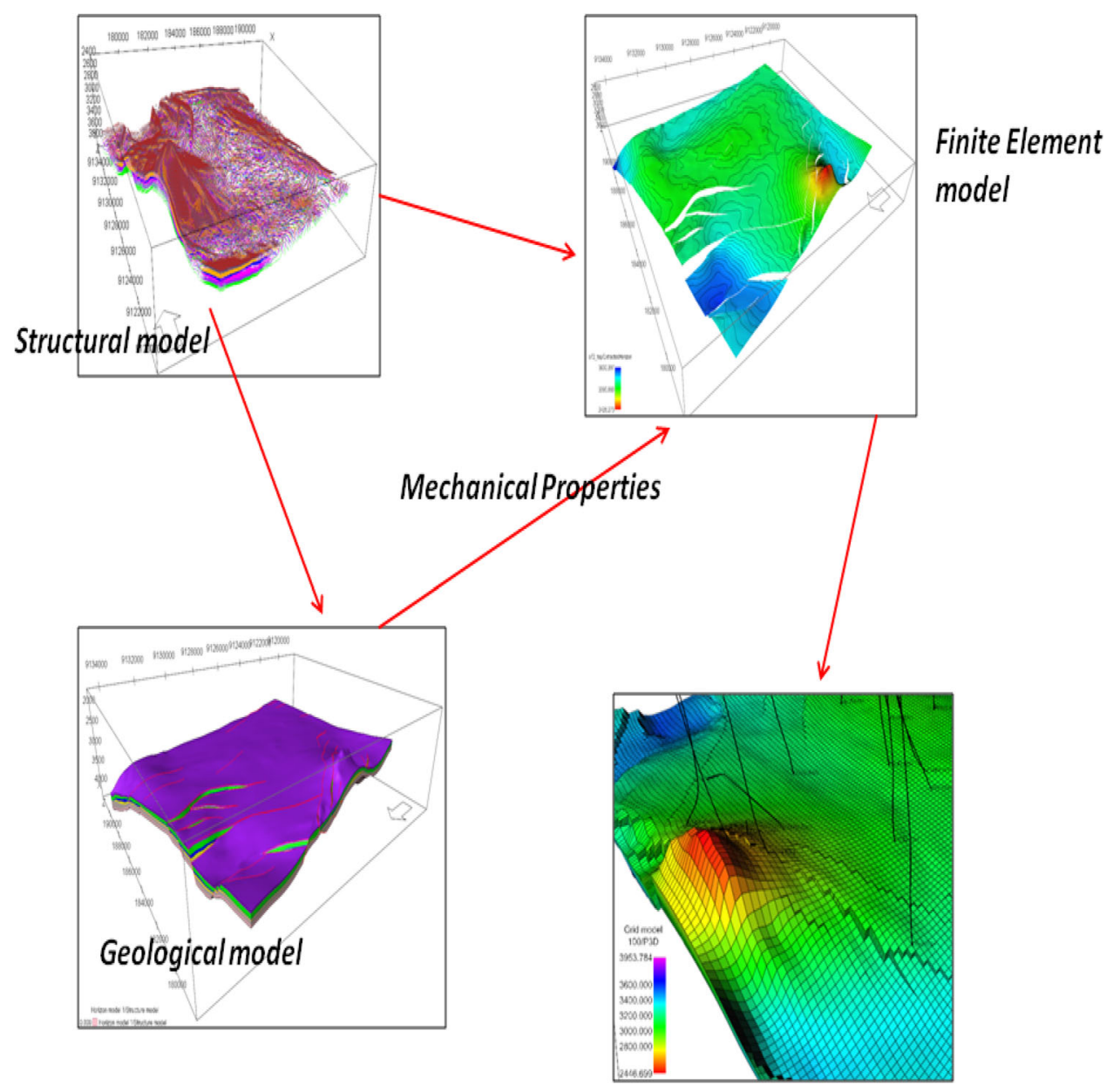

Final 3D stress model

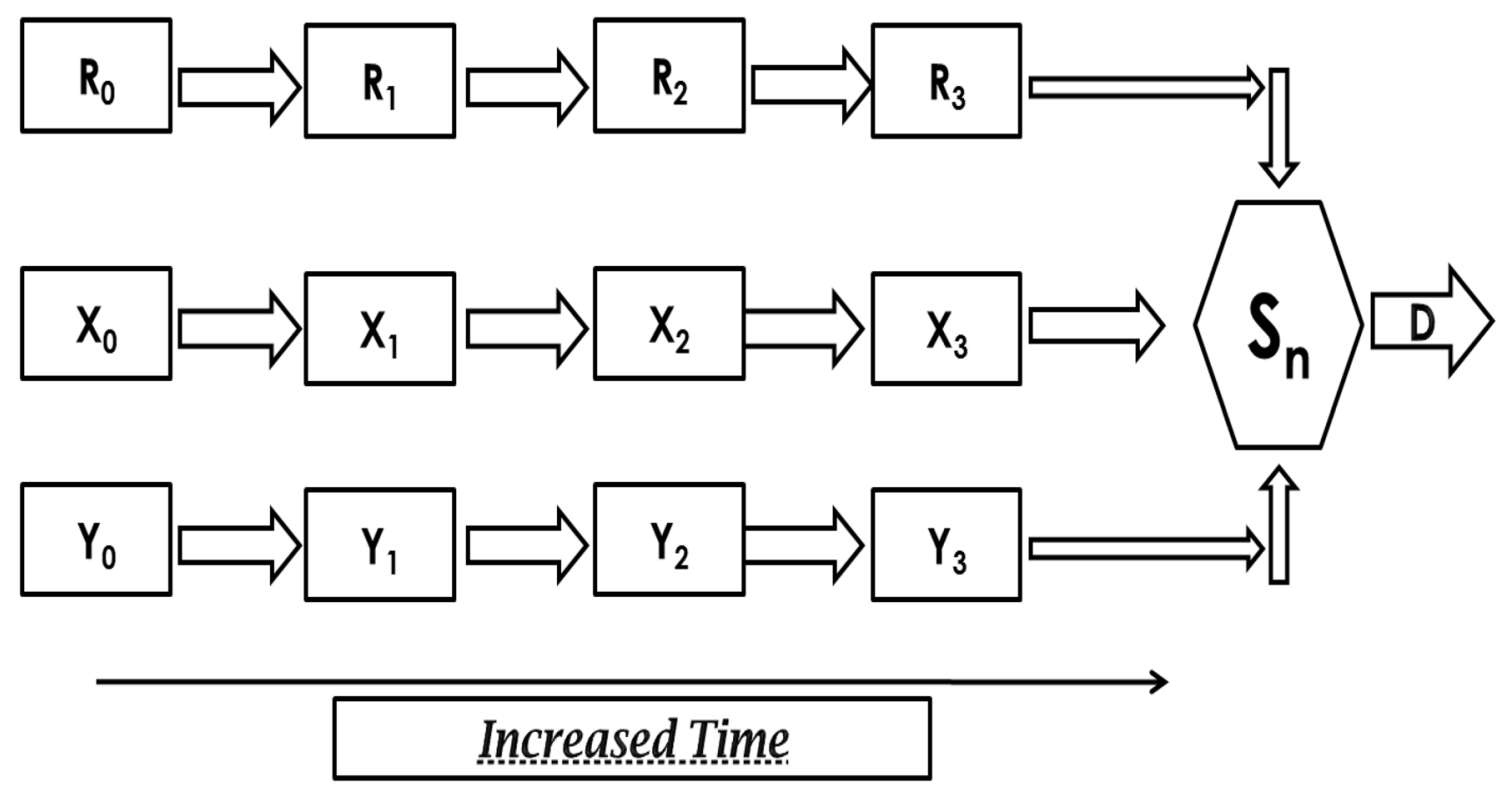

Fig. 5 Standalone reservoir studies workflow. $R, X, Y, S, D$ represent regional geological model, reservoir static model, production/drilling surface facility model and simulation model, respectively $(0,1, n=$ generation) 


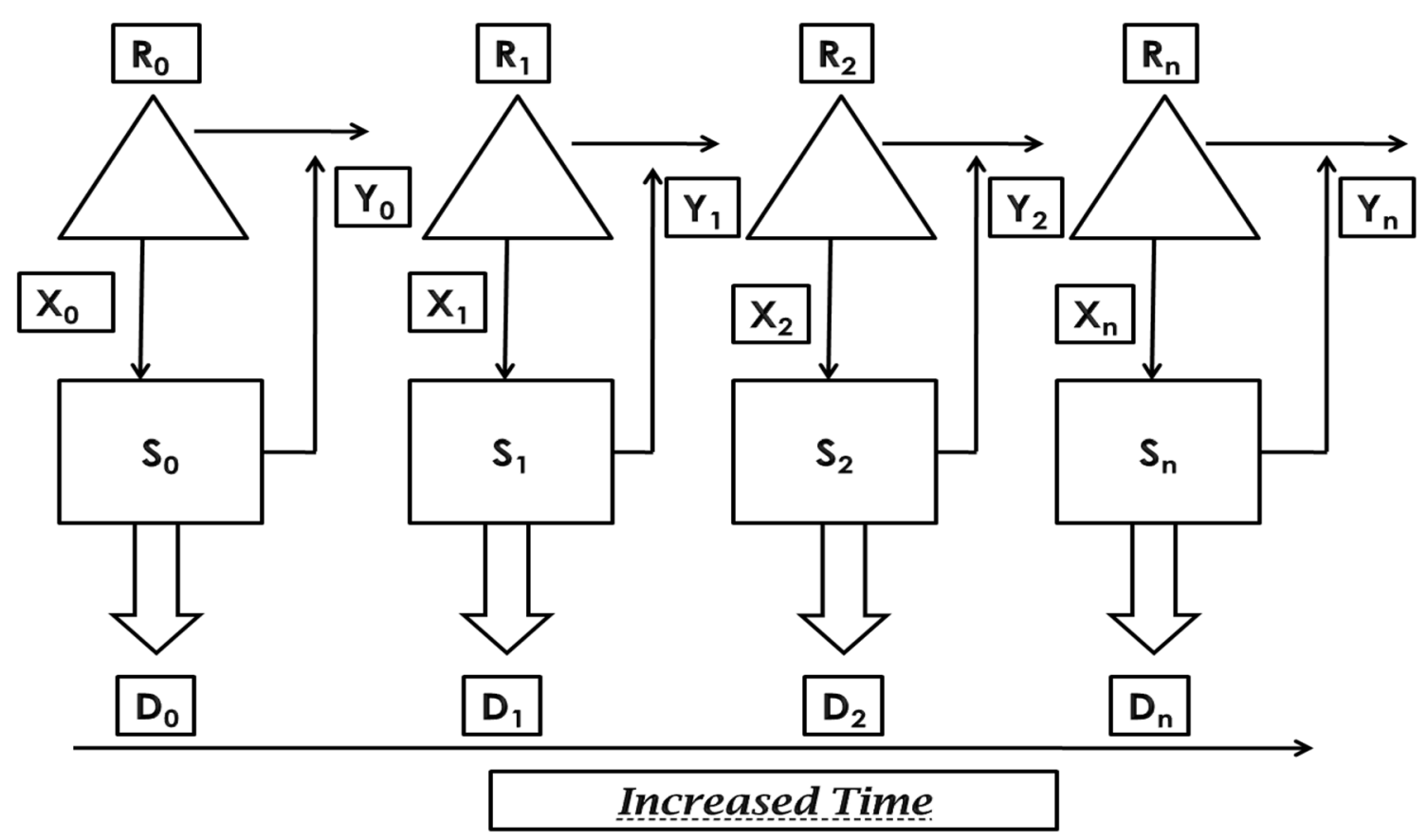

Fig. 6 Integrated reservoir studies workflow. $R, X, Y, S, D$ represent regional geological model, reservoir static model, production/drilling surface facility model and simulation model, respectively $(0,1, n=$ generation)

\section{Methodology}

The proposed model herein is aimed at optimizing the performance of the integrated reservoir study model. The model optimizes the integrated reservoir study model by connecting platforms for collaboration in a logical and physical manner, thereby allowing uninterrupted flow of information throughout the life span of a project and thus eliminating the periodic model structure. Our primary aim is to put forward a system that encourages and allows continuous cross-communication among team members which guarantees the overall success of any oil and/or gas reservoir development project.

In that respect, a global room $X$ is defined here as the base model representing the integrated reservoir studies platform which includes several business nodes $\left(X_{1}, X_{2}\right.$, $\left.X_{3}, X_{4}, \ldots, X_{-1}, X_{n}\right)$ attached to it. These nodes are herein identified as the components for an integrated study or second-tier nodes. In this paper, we consider up to six different components as follows;

- Subsurface modeling and reserves evaluation node $\left(X_{1}\right)$ In this node, the available geomechanical, geophysical, geological, reservoir engineering and petrophysical data are to be interpreted and evaluated, and cutoff values are assigned out of which a representative model and reserves estimation are developed. With this model, main productive units are established.
- Production forecasts and development plans node $\left(X_{2}\right)$ Here, predictions of future production are developed appropriately using techniques such as reservoir simulation, decline curve analysis or material balance methods. Based on these predictions, an optimized development plan is to be designed for the field of interest. This is done in order to economically deplete the recoverable reserves with the highest efficiency.

- Refurbishment plans node $\left(X_{3}\right)$ Here the re-opening of shutdown wells, drilling of new wells, re-activation of some abandoned infrastructure, upgrading the in use infrastructure as well as re-use of suspended infrastructure are considered. Plans are made in respect of these as to best optimize production.

- Health, safety and environment node $\left(X_{4}\right)$ Here a careful look at the potential health, safety and environmental events relevant to the field development program is made. Mitigation and contingency plans are developed so as to ensure an environmentally acceptable operation.

- Capital, operating costs and development schedules node $\left(X_{5}\right)$ Based on the requirements of the field development program in place, individual duties and schedules are developed and assigned for every step of the program. As a result, a comprehensive report which includes the program's budget requirement, production forecast, contingencies and cash flow study is expected to be developed in this node. 
- Economics and production performance node $\left(X_{6}\right)$ Due to the uncertainties in field development, many options can be chosen in order to make development optimizations. Meanwhile, a ranking order of economically acceptable options is made herein. This node is also responsible for making plans in respect of external financial input if the need arises. Again this node makes recommendations with respect to low producing fields, so as to establish the most economically acceptable option, like if abandonment of some of the facilities may result in higher economic performance.

Components are further defined with respect to the second-tier nodes in which every node is composed of its own components. For example, $X_{1}$ covers $X_{1,1}, X_{1,2}, X_{1,3}, X_{1,4}$, $\ldots, X_{1, n-1}, X_{1, n}$. As shown in Fig. 7 , we assume $X_{1}$ represents subsurface modeling and reserve evaluation node, and it is further assumed that its branch $X_{1,1}$ represents regional/geomechanical model, $X_{1,2}$ reservoir scale model, $X_{1,3}$ property model and $X_{1,4}$ lithologic model and so on up to $X_{1, n}$. The procedure can be infinitely continuous.

Based on the proposed model, we assume that a business stream $H$ consists of $N$ business nodes $\left(X_{1}, X_{2}, X_{3}\right.$, $\left.X_{4}, \ldots, X_{n-1}, X_{n}\right)$. Hence, autocorrelation matrix can be applied to express the interaction between every two business nodes in a business stream. Therefore, $r_{i j}$ is defined as a correlation coefficient that represents the cross-correlation between the $i$ th business node and $j$ th business node. Based on the business process stream $H$, its autocorrelation matrix with $N * N$ order is constructed as shown in Fig. 8.

\section{Results and discussion}

\section{Results}

The circles in Fig. 7 represent business nodes and platforms for data sharing and collaborative work, respectively, while the lines connect different business nodes. Arrows show directions of business streams and data streams. Two-way arrows indicate response between nodes and platform. Theoretically, due to its fractal property, this kind of model can be divided further without limitation, thereby enabling a network of different kind of studies. An unlimited opportunity for accepting further study nodes as well as re-evaluation nodes is achieved.

The relationship between business platforms is our prime target, and these platforms are the different specialist involved in a reservoir study as described by Fig. 8, where $r_{i j}$ represents;

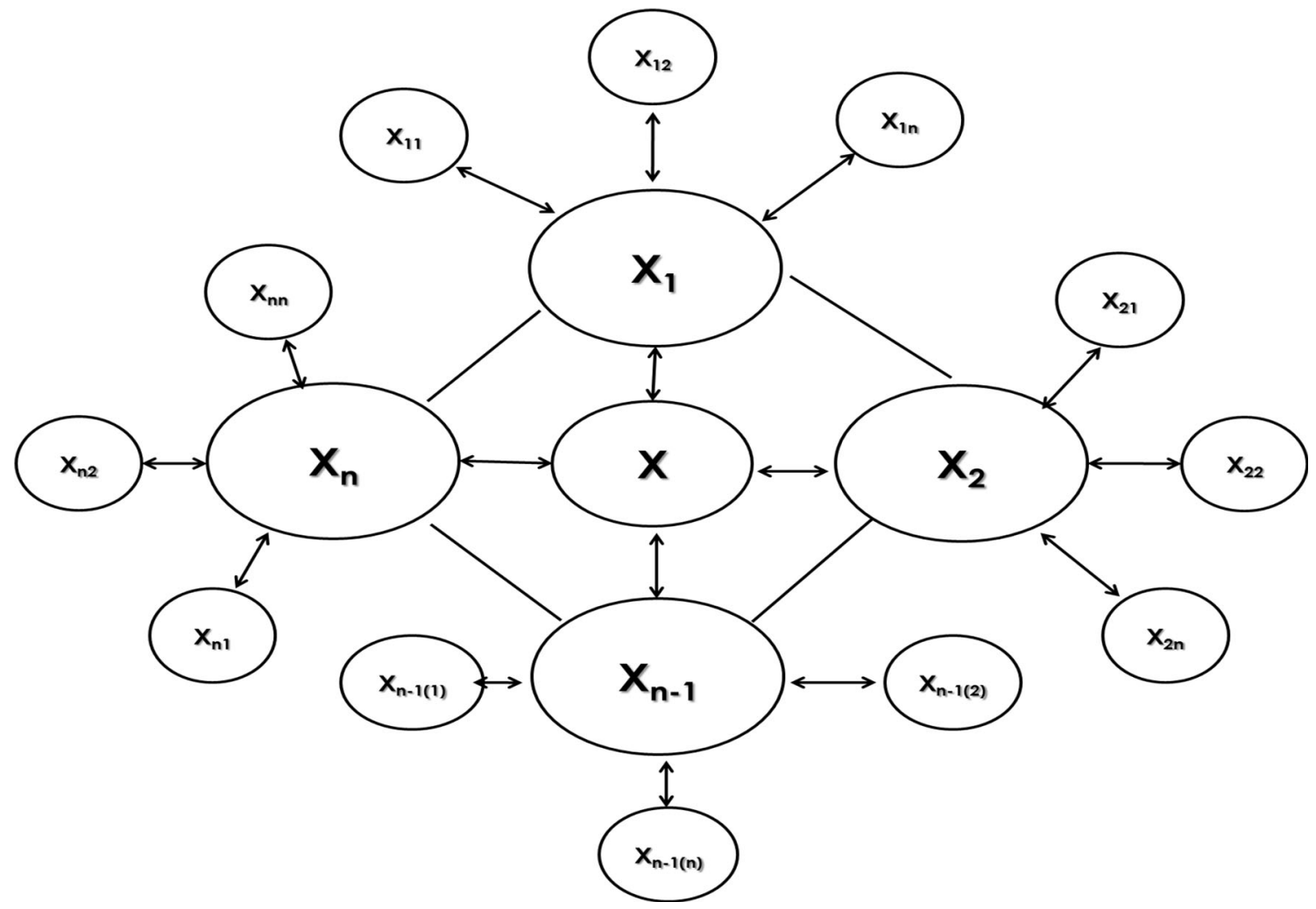

Fig. 7 Optimized integrated reservoir studies workflow 


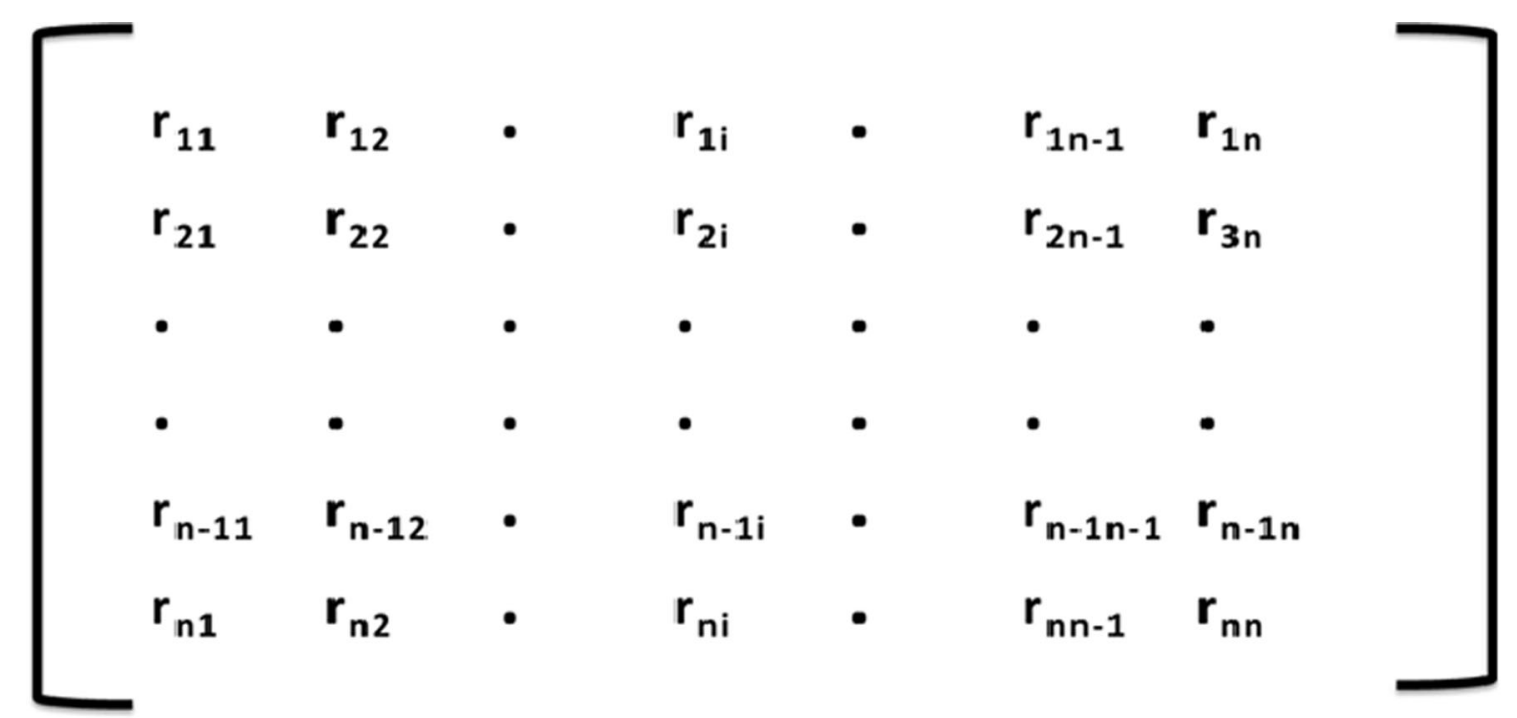

Fig. 8 Interaction matrix

1. Correlation between $i$ th business node and $j$ th business node. $r_{i j}$ will be zero if businesses in the two nodes are separated from each other.

2. Major data delivered from $j$ th business node to $i$ th business node for information exchange and analysis.

3. Materials for publishing and receiving, in the form of maps, graphs, tables, etc. The diagonal line of the matrix divides the matrix into two different sections, in which one is for $i>j$ and the other for $i<j$. If $i>j$, the earlier node in the business process will release data to the later node, and if $i<j$, the later node release data to earlier business node. If $i=j$, any node can share the related data in its own node, but delivered in different time or by different people.

With this application, there will be a quick response and easy visualization of data in a more comprehendible manner, thus making specialist learn from one another and thereby building more confidence. The model expresses integrated reservoir studies in the form of a local world of networks in which each node represents a particular study or business enterprise, while connections between nodes represent information/data exchange. The position of a node in the network reveals the influence and status of its study enterprise on the integrated reservoir study project. The network expansion process will be moving on as the project continues, resulting in network structure alterations.

A study of the network alterations is expected to reveal the structural development of the entire reservoir study, therefore becoming a field of real interest to project managers. By this model, many significant features of the integrated reservoir studies can efficiently be well understood. The model's scale-free correlation degree refers to the fact that the model may have some vital data flow paths that have significant influence on the output of the integrated study, while study enterprise at the end of those flow paths has low correlation degrees. A scale-free connection degree distribution implies that some dominant study enterprise with large number of cooperating nodes attached may be in place. And self-similarity of the model reveals the fact that at different levels of study enterprise such as in regional scale, reservoir scale or well scale, the structural features are similar. Additional features like the local clustering coefficient and/or the average shortest path length can as well be applied to measure the flexibility and response ability of each node with respect to the integrated reservoir study platform $(X)$.

\section{Discussion}

The proposed model provides a platform for a continuous quick parameter analysis unlike the periodic integration approach, thereby allowing a timely decision-making process that considers all probabilities and possible outcomes. Despite the ability to provide better result, risk analysis can easily be performed, and mitigation plans can quickly be designed and optimized. Hence, the value of information can be gathered. This will enable continuous realignment of data gathering methods for better research and development. Flexibility of the model opens up for continuous scalability. Problems can be managed in any resolution, in any detail and within any time frame (unlike the periodic integration previously described). The workflow supports both the top-down approach and bottom-up approach, which we believe can provide a rapid solution to large complex reservoir studies that might have taken far longer duration.

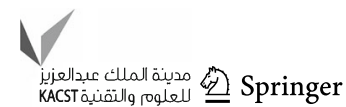




\section{Conclusions}

This work is believed to achieve the optimization of reservoir study models toward a better oil and/or gas field management and thus concludes with the following;

1. The process of petroleum reservoir evaluation has been briefly reviewed in an attempt to showcase the multidisciplinary activities required for in order to achieve a coherent result.

2. Having done that the reservoir study approaches (models) applied in recent times by multidisciplinary teams were discussed, in which a standalone model and an integrated model were identified.

3. Standalone model was identified with limitations; this approach is so much dependent on the accuracy of individual specialist, which might not be guaranteed in some cases. Meanwhile, there tends to be alteration in results, especially when inconsistencies arose during data processing and interpretation.

4. Integrated study was then discussed, in which members of a multidisciplinary team formed for integrated reservoir studies meet periodically to discuss problems and progress, fix possible disagreements as early as possible and solve the problem in a timely and effective manner, thus avoiding the inconsistent result reached by different specialists. This periodic integration was found to lack efficiency, especially in terms of data flow and communication at every step of the project life.

5. The aim of this paper is to emphasize on the need for an optimized approach in the development of petroleum and/or gas reservoir models, and as a result, a concept model was proposed.

6. This proposed model is aimed at optimizing the performance of the periodic integration model by connecting platforms for collaboration in a logical and physical manner, thereby allowing uninterrupted flow of information throughout the life span of a project.

7. The model expresses integrated reservoir studies in the form of a local world of networks in which each node represents a particular study enterprises, while connections in between the nodes represent information/data exchange. A scale-free connection and correlation degree as well as self-similarity nature were adopted in the model so as to balance flexibility of information exchange.

8. A highly integrated workflow coupled with an efficient flow of information leads to an overall optimization of both static, dynamic and geomechanical reservoir models, thereby forming the bases for an efficient field development program. The concept proposed model is expected to create room for modifications and improvement proposed at each step. Model adjustment can progressively be shared among different specialists and managers, while coherency is continuously ensured.

9. With this development, a more economically viable reservoir models can be reproduced.

Open Access This article is distributed under the terms of the Creative Commons Attribution 4.0 International License (http:// creativecommons.org/licenses/by/4.0/), which permits unrestricted use, distribution, and reproduction in any medium, provided you give appropriate credit to the original author(s) and the source, provide a link to the Creative Commons license, and indicate if changes were made.

\section{References}

Aavatsmark I, Eigestad GT, Heimsund B-O, Mallison B, Nordbotten JM, Øian E (2010) A new finite-volume approach to efficient discretization on challenging grids. SPE J 15(03):658-669

Babadagli T (2007) Development of mature oil fields-a review. J Pet Sci Eng 57(3-4):221-246

Benetatos CVD (2010) Fully integrated hydrocarbon reservoir studies: myth or reality? Am J Appl Sci 7:1477-1486

Catuneanu O (2002) Sequence stratigraphy of clastic systems: concepts, merits, and pitfalls. J Afr Earth Sc 35(1):1-43

Chen Y, Oliver DS (2014) History matching of the norne full-field model with an iterative ensemble smoother. SPE J 17(02):244-256

Cosentino L (2001) Integrated reservoir studies. Technip, Paris

Delshad M, Thomas SG, Wheeler MF (2011) Parallel numerical reservoir simulations of nonisothermal compositional flow and chemistry. SPE J 16(02):239-248

Doublet LE, Pande PK, Clark MB, Nevans JW, Blasingame TA (1995) An integrated geologic and engineering reservoir characterization of the North Robertson (Clearfork) Unit: a case study, part 1 . Society of Petroleum Engineers, Richardson

Farag SM, Mas C, Maizeret P-D, Li B, Le HV (2010) An integrated workflow for granitic basement reservoir evaluation. SPE Reserv Eval Eng 13(06):893-905

Fitch P, Davies S, Lovell M, Pritchard T (2013) Reservoir quality and reservoir heterogeneity: petrophysical application of the Lorenz coefficient. Petrophysics 54(05):465-474

Gu F, Chan MYS, Fryk R (2011) Geomechanical-data acquisition, monitoring, and applications in SAGD. J Can Pet Technol 50(06): $9-21$

Gunning J, Paterson L (2001) Conditioning of Lévy-stable fractal reservoir models to seismic data. SPE J 6(02):137-143

Habidin NF, Yusof SM (2012) Relationship between lean six sigma, environmental management systems, and organizational performance in the Malaysian automotive industry. Int $\mathrm{J}$ Automot Technol 13(7):1119-1125

Huang NS, Aho GE, Baker BH, Matthews TR, Pottorf RJ (2011) Integrated reservoir modeling of a large sour-gas field with high concentrations of inerts. SPE Reserv Eval Eng 14(04):398-412

Kim J, Tchelepi HA, Juanes R (2013) Rigorous coupling of geomechanics and multiphase flow with strong capillarity. SPE J 18(06):1123-1139

Knackstedt M, Carnerup A, Golab A, Sok R, Young B, Riepe L (2013) Petrophysical characterization of unconventional reservoir core at multiple scales. Petrophysics 54(03):216-223 
Le Ravalec-Dupin M, Enchery G, Baroni A, Da Veiga S (2011) Preselection of reservoir models from a geostatistics-based petrophysical seismic inversion. SPE Reserv Eval Eng 14(05):612-620

Mallison B, Sword C, Viard T, Milliken W, Cheng A (2014) unstructured cut-cell grids for modeling complex reservoirs. SPE J 19(02):340-352

Mardani A, Rezaee R, Asadi A (2013) NMR facies definition for Permo-Triassic Kangan/Dalan carbonate formation by use of core/log and pore-scale measurements. SPE J 16(01):8-18

Merletti GD, Torres-Verdin C (2010) Detection and spatial delineation of thin-sand sedimentary sequences with joint stochastic inversion of well logs and 3D prestack seismic amplitude data. SPE Reserv Eval Eng 13(02):246-264

Møyner O, Lie K-A (2014) The multiscale finite-volume method on stratigraphic grids. SPE J 19(05):816-831

Panfili P, Cominelli A, Calabrese M, Albertini C, Savitsky A, Leoni G (2012) Advanced upscaling for kashagan reservoir modeling. SPE Reserv Eval Eng 15(02):150-164

Sawaryn SJ, Whiteley N, Deady A, Borresen A, Gibson N (2011) The influence of data quality on workflows and decision-making in well delivery. SPE Drill Complet 26(01):36-40

Thomas LK, Chin LY, Pierson RG, Sylte JE (2003) Coupled geomechanics and reservoir simulation. SPE J 08(04):350-358

Vidal-Gilbert S (2010) Investigation of the effect of rock mechanical properties and in-situ stresses on seismic velocity through a coupled geomechanical reservoir model. SPE Reserv Eval Eng 13(02):332-340

Warpinski NR, Mayerhofer M, Agarwal K, Du J (2013) Hydraulicfracture geomechanics and microseismic-source mechanisms. SPE J 18(04):766-7780

Worthington PF (2011) The petrophysics of problematic reservoirs. J Pet Technol 63(12):88-97

Worthington PF, Cosentino L (2005) The role of cut-offs in integrated reservoir studies. SPE Reserv Eval Eng 08(04):276-290

Wouter van der Zee CO, Brudy M, Holland M (2011) 3D geomechanical modeling of complex salt structures. In: SIMULIA customer conference. Baker Hufges, Germany

Wu X-H, Parashkevov R (2010) Effect of grid deviation on flow solutions. SPE J 14(01):67-77

Xie CJ, Guan ZL, Blunt M, Zhou H (2009) numerical simulation of oil recovery after cross-linked polymer flooding. J Can Pet Technol 48(04):37-41

Zett A, Webster M, Davies CJ, Zhang P, Mukerji P (2010) Integrated surveillance enhancing quality of decisions and reservoir description in the harding field. SPE Reserv Eval Eng 13(05):805-811

Zhang ZL (2005) Architecture of oil exploration and production data integration flat. J China Univ Pet 29(1):131-135

Zhao G, Wang Y, Cui Q, Cui S (2010) The construction and application of data warehouse for oil exploration and development. Geochem Geophys Explor 34(1):108-110 